\title{
0 Chat Como Espaço de (Inter)locuções: uma leitura a partir das idéias de Bakhtin
}

\author{
The Chat how space of inter(locution): \\ a reading from the ideas of Bakhtin
}

Resumo: Este artigo foi desenvolvido no contexto de uma disciplina do curso de pós-graduação em educação e informática na educação da Universidade Federal do Rio Grande do Sul e busca propor uma análise de conversações que tenham ocorrido em chats. A partir do estudo da teoria de Mikhail Bakhtin, pensamos o ambiente do chat como possuidor de uma pragmática comunicacional que se alicerça em conceitos trabalhados pelo autor. Para tanto, analisamos os diálogos entre os participantes tendo em vista o locutor e o interlocutor, os enunciados proferidos, a compenetração e a produção de sentidos, os elementos de entonação, a alternância entre vozes e situação espaço temporal. Consideramos que no chat estabeleceu-se uma cadeia dialógica na qual estava presente uma multiplicidade de vozes. Para caracterizar a alternância entre as vozes, a demarcação dos elementos de entoação foi de extrema importância. Concluímos que o chat pode ser considerado um canal propício para discussão e construção conceitual, numa dimensão espaço temporal, permitindo que diferentes participantes pudessem se colocar com suas singularidades expressas nos seus enunciados em forma escrita.

Palavras-chave: Chat. Educação a Distância. Análise de enunciados. Bakhtin, Mikhail.

Abstract: The development of this article is immersed in the context of a coursework of the graduate course in education and information technology in education at Federa University of Rio Grande do Sul and aims to investigate discussions occurred in chats. Starting from the study of the theory of Mikhail Bakhtin, we conceive the environment of the chat as holder of a communication pragmatics which is based on concepts designed by the author. For this purpose, we analyzed the dialogues among the participants in view of the speaker and interlocutor, statements given, the concentration and production of meaning, the elements of intonation, the switching among voices and space-time situation. We believe that a dialogical chain was set up in the chat, in which there were a variety of voices. In order to typify the switching among the voices, the demarcation of the elements of intonation was extremely important. We conclude that the chat can be considered a favorable channel for discussion and conceptual construction within a space-time dimension, and it enables different participants to express their singularities through written statements. Keywords: Chat. Distance education. Analysis of statements. Bakhtin, Mikhail.

SILVEIRA, André Luis Marques da; MACHADO, Magale; CHARCZUK, Simone Bicca. O Chat Como Espaço de (Inter) locuções: uma leitura a partir das idéias de Bakhtin. Informática na Educação: teoria \& prática, Porto Alegre, v. 11, n. 2, p. 90-101, jul./dez. 2008. \author{
André Luis Marques da Silveira \\ Magale Machado \\ Universidade Federal do Rio Grande do Sul \\ Simone Bicca Charczuk \\ Universidade Federal do Rio Grande do Sul
}

\section{I ntrodução}

$C_{\mathrm{v}}^{\mathrm{t}}$ om a ascensão da utilização da informática, mais precisamente da internet, na vida cotidiana, canais de conversa síncrona, denominados Chats, são cada vez mais utilizados para acolher o diálogo entre pessoas. Da mesma forma, em modalidades de educação a distância, esse recurso é utilizado para a comunicação entre os participantes de determinada disciplina ou curso para a troca de informações, esclarecimento de dúvidas ou para a discussão de um assunto ou tópico que está sendo trabalhado.

Bernardes e Vieira (2001) caracterizam o Chat como um projeto discursivo de conversação que utiliza, para sua efetivação, um software específico. Geralmente, em educação a distância, o software que suporta o Chat está agregado a um ambiente que suporta também outros recursos tais como fóruns de discussão, portfólios (ou webfólios), diários de bordo etc. Ressaltam ainda que os enunciados que são produzidos nesses ambientes se constroem como um texto falado por escrito (HIL- 
GERT, 2000 apud BERNARDES; VIEIRA, 2001). Ressaltamos também a construção conceitual coletiva dos autores envolvidos num momento de estudo e discussão no ambiente virtual para aprendizagens.

Tendo em vista a potencialidade do Chat como espaço de produção discursiva e canal de visibilidade de enunciados, esse trabalho tem como objetivo a leitura de um Chat $^{1}$ realizado em uma disciplina oferecida pelos cursos de pós-graduação em educação e em informática na educação da Universidade Federal do Rio Grande do Sul. O Chat em questão versava sobre o texto de Bakhtin Os Gêneros do Discurso e foi realizado no dia três de abril de 2008 com a participação de 19 pessoas.

\section{Metodologia de Análise}

Consideramos que termos acesso assincronamente aos registros das interações sincrônicas em ambiente virtual de aprendizagem nos auxilia no estudo sobre a complexidade da linguagem em plena funcionalidade, baseando-nos na vivência da educação a distância e em elementos da teoria de Mikhail Bakhtin. Precisamos tomar uma posição de certo estranhamento em relação ao material a ser analisado, uma vez que também participamos na produção dos enunciados no Chat, a fim de encontrar um distanciamento que nos permita uma interrogação e suspensão da evidência no texto com o qual nos encontramos neste corpus. Nesse sentido, entendemos que ocupamos o lugar de terceiro ${ }^{2}$ que tenta emoldurar compreensivamente o texto.

Buscamos uma nova posição espaço-temporal que nos permita uma relação de alteridade com o texto que encontramos no Chat, realizando novos encontros com ele, permitindo um texto sobre o outro texto. Outro aspecto importante do artigo que se desenrola neste momento, é que o mesmo se fundou

\footnotetext{
${ }^{1} \mathrm{O}$ chat está agregado ao Ambiente Virtual de Aprendizagem TelEduc: http://teleduc.cinted.ufrgs.br.

2 Conforme Bakhtin (2003, p. 333), o terceiro pode ser compreendido como um “[...] superdestinatário superior, cuja compreensão responsiva absolutamente justa ele pressupõe quer na distância metafísica, quer no distante tempo histórico [...]". O terceiro, para Bakhtin (2003), é aquele que não participa do diálogo, mas o entende. Logo adiante destaca que "[...] cada diálogo ocorre como que no fundo de uma compreensão responsiva de um terceiro invisivelmente presente, situado acima de todos os participantes do diálogo (parceiros) [...]" (BAKHTIN, 2003, p. 333).
}

em co-autoria de três colegas participantes da disciplina. O fato de nos colocarmos como três autores nos fez pensar na discussão da relação entre os sujeitos no texto. Aqui temos pelo menos três. Referimo-nos a co-autoria para ressaltar a consideração dos diferentes sujeitos que estão presentes neste artigo, tanto na nossa voz que portam em si outras vozes, como nos enunciados de que lançaremos mão para as análises.

A partir da idéia apresentada por Bakhtin, de que a linguagem está presente em todos os campos da atividade humana e que a interação entre os interlocutores de uma conversa possui caráter dialógico, pode-se compreender o Chat como um espaço privilegiado para o desenrolar de uma conversa. Assim, o Chat pode ser compreendido como espaço no qual vários enunciados podem ser proferidos, idéias discutidas, concordadas ou contrapostas.

Em relação ao corpus de análise, optamos por trabalhar com 13 enunciados nos quais se engajaram quatro participantes. Nesse extrato do Chat, os participantes dialogaram sobre as diferenças entre estilo e gênero de discurso para Bakhtin. Em relação ao material coletado no Chat, buscamos analisar os enunciados tendo em vista: os locutor e interlocutor, a situação no tempo-espaço, os elementos de entonação, a alternância entre vozes e a produção de sentido.

\section{Locutor, o Segundo Locutor, o(s) Terceiro(s) Locutor(es) na Relação Entre os Enunciados Proferidos e Suas Vozes}

Tendo em vista a sintaxe comunicacional estabelecida pelo sistema de Chat, para a emissão dos enunciados que foram analisados, detectamos que o ato interlocutivo se faz presente de forma explícita no processo comunicacional do ambiente. A noção de interlocução aqui adotada exige o envolvimento de, no mínimo, dois participantes do Chat em determinada situação de comunicação. Para que a interlocução se efetive é necessário um locutor (o sujeito que fala ou escreve) e de alguém a quem a enunciação é dirigida (o interlocutor).

A seguir é exemplificada a sintaxe comunicacional do Chat: 


\begin{tabular}{|c|c|c|c|l|}
\hline Hн:MM:SS & Locutor & Ação & interlocutor & \multicolumn{1}{c|}{ Mensagem } \\
\hline$(16: 11: 23)$ & Ave & $\begin{array}{c}\text { fala } \\
\text { para }\end{array}$ & Todos & $\begin{array}{l}\text { Alguém conseguiu distinguir } \\
\text { estilo de gênero para bakhtin? } \\
\text { Poderíamos tentar esmiuçar essa } \\
\text { questão }\end{array}$ \\
\hline
\end{tabular}

Nos enunciados a seguir, podemos identificar o locutor como GUA e MIS e seus respectivos interlocutores como AVE e TODOS.

(16:15:45) GUA fala para AVE: Boa pergunta: DES CONFIO QUE gêneros tem mais a ver com formatos de discurso inerentes a campos comunicacionais, ENQUANTO estilos se referem mais às diferenças individuais no exercício da comunicação discursiva nos diversos gêneros.

(16:18:50) MIS fala para TODOS: “EM cada campo existem e são empregados gêneros que correspondem às condições específicas de dado campo; É A ESSES gêneros que correspondem determinados estilos" (p. 266). AGORA traduzam hehe.

Entretanto, através do enunciado de MIS (16:18:50) podemos identificar um terceiro locutor, o próprio Bakhtin. A utilização deste recurso denota uma marca que revela a apropriação da palavra do outro no discurso do falante.

Cabe ressaltar também o uso do conectivo e o do vocativo nas falas dos interlocutores. O conectivo é explicitado através da sintaxe adotada pelo Chat, quando o locutor dirige a palavra para o interlocutor ele obrigatoriamente tem que se dirigir para alguém, GUA fala para AVE.

Quando um locutor deseja dirigir a palavra a todos os participantes do Chat, ele irá adotar o destinatário TODOS. A partir da análise dos enunciados que utilizavam o destinatário TODOS, percebemos a presença, em alguns casos, de um vocativo que aponta para um outro destinatário, mantendo assim, ao mesmo tempo, o direcionamento do enunciado tanto para um destinatário geral (TODOS) quanto particularizando esse direcionamento através do vocativo. O vocativo é compreendido como único termo isolado dentro da oração. Não faz parte do sujeito nem do predicado, sua função é chamar ou interpelar o destinatário a quem se está dirigindo a palavra. Nos casos em que o vocativo e o conectivo se referem ao mesmo destinatário, pode-se interpretar como sendo uma possível redundância na comunicação, um chamado que foi enfatizado.

Abaixo, fragmentos de todos os enunciados analisados que apresentam esta situação.

(16:15:53) AVE fala para TODOS: sim, é um pouco por aí, GUA

(16:32:48) GUA fala para AVE: Que golpe baixo, AVE !

(16:33:54) AVE fala para ToDos: desculpe pelo "golpe baixo" GUA

\section{A Pragmática Comunicacional do Chat}

Consideramos que, no Chat analisado, estabeleceu-se uma cadeira dialógica entre os enunciados dos interlocutores. Os enunciados proferidos, em quase toda a sua totalidade, foram orientados para a produção de sentidos, mediante a formulação de seqüências lingüísticas verbalizadas de pensamento que buscaram operar sobre os interlocutores tendo em vista o ato de compreender a significação dos enunciados anteriores e do estabelecimento de relações entre os mesmos. Consideramos o acabamento com uma abertura para outros e novos efeitos de sentido e certa estabilidade entre os enunciados que nos levam e pensar numa compreensão responsiva, que também porta em si uma abertura para outras possibilidades de compreensão. Para caracterizar a alternância entre vozes, demarcamos os elementos de entonação presentes nos enunciados. Eles auxiliaram a explicitar os recursos expressivos e o acabamento adotados. Também, buscamos identificar a situação tempoespaço, tendo em vista o horizonte compartiIhado pelos interlocutores.

A pragmática que se apresenta no esquema a seguir busca ilustrar uma maneira de entender a dinâmica na interação entre os inter- 
locutores que confere alguns detalhamentos intrínsecos na relação entre enunciados que também decorrem na possibilidade de produção de sentidos, numa cadeia dialógica nas (discussões e) construções conceituais.

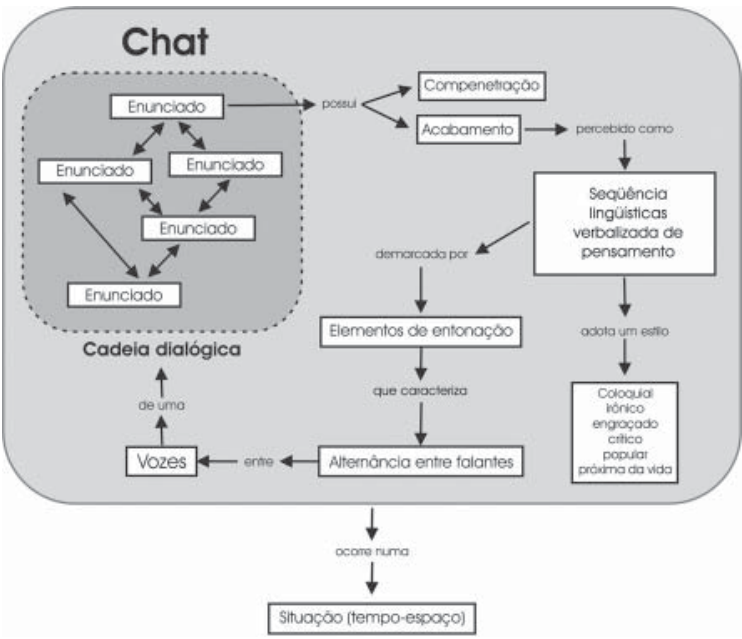

FIGURA 1 - Uma Visão Esquemática da Pragmática Comunicacional no Chat.

\section{A Situação no Tempo-Espaço}

Cabe ressaltar que o discurso no Chat analisado é composto por uma parte verbal e uma extraverbal que o engendrou. A parte verbal compreende aquilo que é dito no enunciado, já a parte extraverbal compreende o presumível, a situação no tempo-espaço em que os enunciados são proferidos pelos interlocutores do discurso. O presumido do discurso compreende todo o horizonte (social, histórico e ideológico) compartilhado pelos interlocutores. Bakhtin trabalha com uma percepção do espaço e do tempo em fusão, considera o espaço impregnado de acontecimentos precisos presentes nas enunciações. Um acontecimento é rigorosamente localizado e se exprimem nos indícios que marcam os tempos. Nas palavras de Bakhtin:

O ambiente se tornou parte insubstituível do mundo geográfica e historicamente definido, desse mesmo mundo plenamente real e essencialmente visível da história humana e o acontecimento se tornou um momento essencial e intransferível no tempo dessa história humana definida, que se realiza exclusivamente nesse mundo humano historicamente definido. (BAKHTIN, 2003, p. 254)
Desta forma, o discurso não pode ser desvinculado da parte extraverbal. Ela faz parte da produção de discurso e de sentido. Também consideramos importante destacar a coparticipação dos sujeitos no ato de formular uma compreensão do enunciado, que terá relação com a produção de sentido. A formulação desse diálogo precisa ser construída com características que vão além da troca de palavras entre os interlocutores, precisa ser construída tendo em vista a interação de múltiplas vozes. Abaixo, extrato do Chat exemplificando a co-participação dos sujeitos no discurso e a interação entre vozes.

(16:11:23) AVE fala para TODOS: ALGUÉM CONSEGUIU distinguir estilo de gênero para bakhtin? PODERÍAMOS TENTAR esmiuçar essa questão

(16:15:57) NAI fala para TODOS: VOU ME ARRISCAR a falar alguma coisa sobre..... COM BASE no que entendi sobre o que li...; PARA MI M, o estilo caracteriza o gênero.

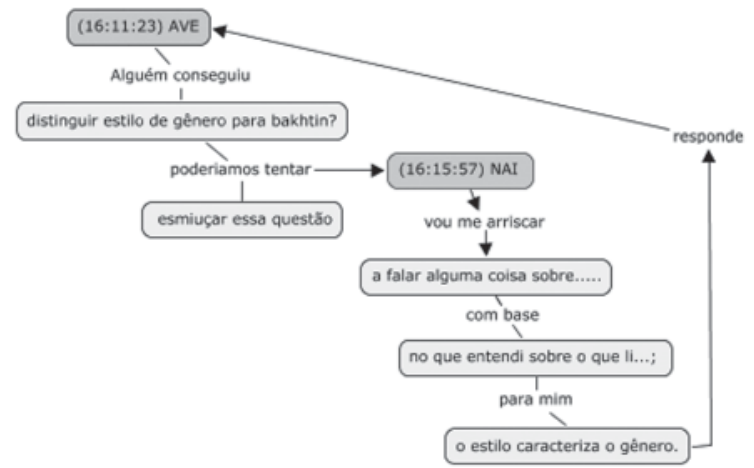

FIGURA 2 - Mapa Conceitual Ilustrando uma Situação Extraverbal

Da mesma forma, o contexto espaço-temporal no qual se desenvolveu o Chat deve ser compreendido como de suma importância para pensarmos as relações verbais e extraverbais acima mencionadas. Nesse sentido, é necessário pensarmos o Chat como um evento datado, ou seja, como uma situação que ocorreu no contexto de uma disciplina no primeiro semestre letivo de 2008. Tal disciplina estava vinculada institucionalmente aos programas de pós-graduação em educação e informática em educação da Universidade Federal do Rio Grande do Sul e teve como participantes alunos de programas de mestrado e doutorado da referida instituição. 


\section{Os Enunciados, as Vozes e a Cadeia Dialógica}

Assumimos como pressuposto que é somente na interação de um locutor com um interlocutor - em dada situação específica - que um enunciado ganha sentido. Os enunciados podem ser considerados como o emprego da língua que refletem as condições específicas e finalidade de cada campo (pelo conteúdo, estilo da linguagem e construção composicional). No enunciado comunicacional o ouvinte deve ser compreendido como parte ativa e responsiva do processo, ou seja, em última instância o ouvinte torna-se também falante.

Além disto, para Bakhtin, o conceito de vozes compreende a idéia de que tudo que é enunciado por um falante não pertence somente a ele, pois em seu discurso podem ser percebidas outras tantas vozes. O discurso individual é composto por vozes de outros que podem ser modificadas, assimiladas, que podem ser ouvidas ou mascaradas. Essas vozes dialogam entre si, representam pontos de vista em constante interação e conflito. São essas vozes que podem ser compreendidas como portadoras e produtoras de efeitos de sentido 3 (BRAIT, 1999). A composição do enunciado por vozes é que dá a ele seu caráter polifônico. Para Bakhtin (2003, p. 330), “[...] em cada palavra há vozes às vezes infinitamente distantes, anônimas, quase impessoais [...], quase imperceptíveis, e vozes próximas, que soam concomitantemente."

No diálogo as vozes (a parte das vozes) se soltam, soltam-se as entonações (pessoais emocionais), das palavras e réplicas vivas extirpar os conceitos e juízos abstratos, mete-se em tudo em uma consciência abstrata. (BAHKTIN, 2003, p. 383).

Esse encontro de consciências na cadeia dialógica, que ocorre através da comunicação discursiva, caracteriza um evento social e a comunicação humana realiza-se através de discursos em que se encontram vozes..

No enunciado abaixo, o locutor AVE (16:11:23) assume uma voz de questiona-

\footnotetext{
3 Para Bakhtin (2003) o sentido é produzido na interação de discursos, se dá no movimento dialógico e depende da presença do outro. Segundo o autor, “[...] os sentidos estão divididos entre vozes diferentes [...]" (BAKHTIN, 2003, p. 320).
}

mento e seu enunciado convoca, a partir de uma pergunta, os demais participantes do Chat para o debate sobre uma determinada problematização. No enunciado do locutor ecoa uma voz de autoridade. Consideramos que a ação daquele que profere uma voz professoral deva assemelhar-se a de um gestor da comunicação. O mesmo deve promover situações que possibilitem a participação ativa e crítica dos estudantes na construção do conhecimento.

(16:11:23) AVE fala para TODos: ALGUÉM CONSEGUIU destinguir estilo de gênero para bakhtin? PODERíAMOS TENTAR esmiuçar essa questão

Na seqüência do diálogo entre GUA e AVE, a voz de Bakhtin aparece internamente dialogizada com o discurso dos participantes, não sendo possível uma separação entre o que é discurso do autor e o que é discurso do participante. AVE em (16:15:53), propõe uma resposta ao enunciado que GUA (16:15:45) formula para o seu interlocutor em AVE (16:11:23).

(16:15:45) GUA fala para AVE: Boa pergunta: DESCONFIO QUE gêneros tem mais a ver com formatos de discurso inerentes a campos comunicacionais, ENQUANTO estilos se referem mais às diferenças individuais no exercício da comunicação discursiva nos diversos gêneros.

(16:15:53) AVE fala para TODOS: SIM, é um pouco por aí, GUA, ESSA É uma noção interessante para Bakhitn... o início do meu discurso, e até mesmo a minha autoria, estão sempre na dependência do outro, mas de um outro que é um pouco mais amplo do que o outro falante, mas engloba a própria cultura. DESSA FORMA, mesmo a mais simples comunicação interpessoal é um fenômeno, antes de tudo, cultural. ASSIM COMO uma obra em vários tomos, como "A comédia humana", de balzac, É também enunciado, pois também é uma obra posta num circuito de comunicação primordialmente cultural

Logo após o enunciado de AVE (16:11:23), MIS formula seu primeiro enunciado em (16:13:31). Para compor seu próximo enunciado, MI S (16:18:50) utiliza a voz de Bakhtin que é destacada no texto através do uso das aspas. A utilização deste recurso denota uma marca que revela a apropriação da palavra do outro no discurso do falante. Entretanto, isto 


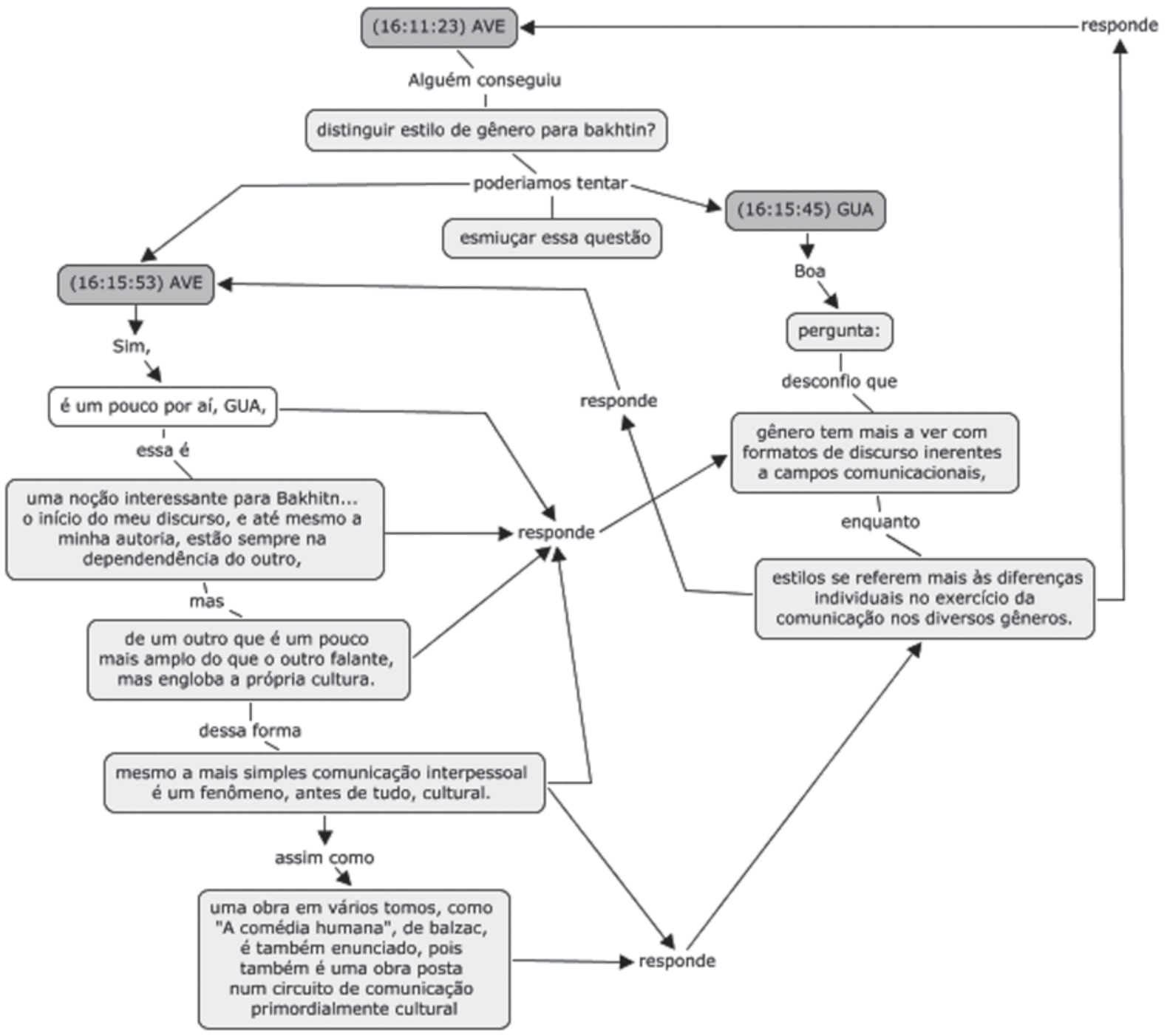

FIGURA 3 - Mapa Conceitual Ilustrando Interações Entre os Participantes

não possibilita afirmar que a palavra do outro tenha sido compreendida pelo falante. Como já havíamos citado na página 4, esta voz é identificada como outro locutor que dirige sua fala a TODOS os envolvidos, inclusive a própria MI S.

Como MIS (16:18:50) parece não compreender o enunciado proferido por BAKTHI N (00:00:00) (a voz de Bakhtin proferida pela própria MIS), ela adota um tom irônico e acrescenta à resposta dele uma resposta de caráter afirmativo para o destinatário TODOS.

(16:13:31) MIS fala para TODOS: diferença entre estilo e gênero... VAMOS VER ...

(16:18:50) MIS fala para TODOS: “EM cada campo existem e são empregados gêneros que correspondem às condições específicas de dado campo; É A ESSES gêneros que corres- pondem determinados estilos" (p. 266). AGORA traduzam hehe

Nos enunciados acima citados, podemos destacar que AVE (16:11:23) dirigiu um questionamento a TODOS os participantes do Chat. Mis (16:13:31) e Mis (16:18:50) dirigiu também a TODOS a sua resposta em relação ao enunciados anteriores. Já GUA (16:15:45) vai dirigir sua resposta diretamente à AVE (16:11:23). Em seguida AVE (16:15:53) dirige sua resposta a TODOS e a GUA (mediante o uso do conectivo e do vocativo). Orientamonos pelo fato de que o enunciado sempre tem um destinatário de “[...] índole variada, graus variados de proximidade, de concretude, de compreensibilidade etc [...]" (BAKHTIN, 2003, p. 333). Este destinatário, identificado como GUA, é nomeado por Bakhtin como sendo o segundo destinatário. Assim, consideramos 


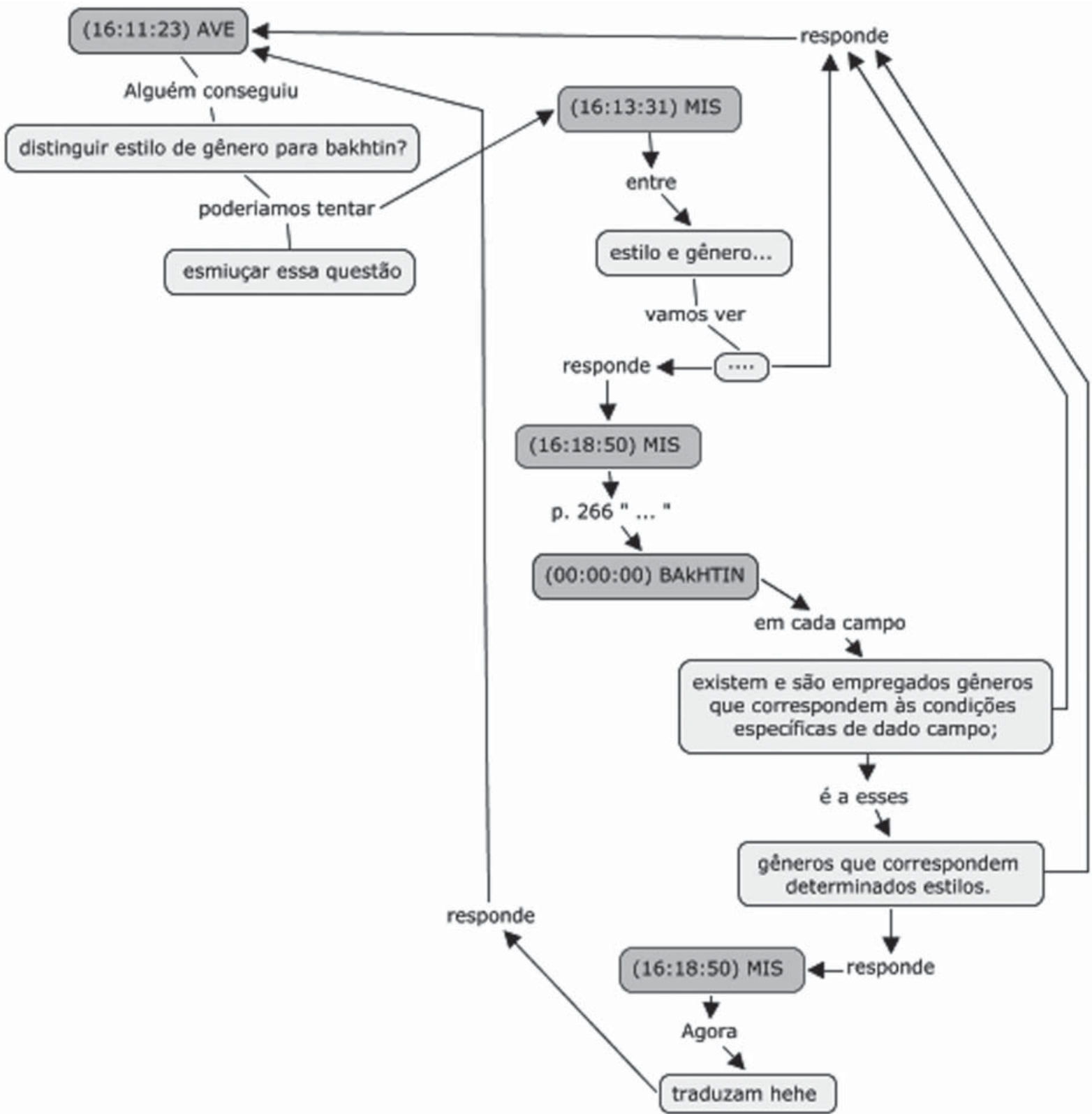

FIGURA 4 - Mapa Conceitual Ilustrando a Existência de um Outro Locutor

em AVE (16:15:53) como um segundo destinatário de GUA. Também podemos considerar que quanto AVE (16:11:23) e MI S (16:13:31) se dirigem a TODOS eles podem estar se dirigindo a um leitor imediato no ambiente, um segundo destinatário, mas também podem estar fazendo menção a uma maior distância entre os participantes, mediada por um terceiro destinatário do qual ainda não se sabe. Ao se tecer um texto, na interação, uma construção discursiva coletiva, podemos presumir um terceiro mais distante que vem a operar a possibilidade de abertura e de alteridade entre os interlocutores, o que pode ser propício para a produção de sentido.
Para Bakthin (2003), os enunciados estabelecem relações dialógicas que se expressam na linguagem através das diferentes posições apreciativas dos sujeitos a respeito de um tema ou objeto. No caso do discurso, pode-se dizer que seu caráter dialógico é determinado pela relação deste com outros discursos ditos e não ditos e com a orientação deste em relação à resposta ativa do leitor/interlocutor. Esse encontro de consciências na cadeia dialógica, que ocorre através da comunicação discursiva, caracteriza um evento social.

Toda a vida da linguagem, seja ela qual for o seu campo de emprego (a linguagem cotidiana, a prática, a científica, a artística etc.) está 
impregnada de relações dialógicas. (BAKHTIN, 2003, p. 183)

Segundo o autor, a comunicação humana realiza-se através de discursos em que se encontram vozes. Desta forma, o enunciado é sempre construído em interação constante e contínua com os enunciados dos outros, exprimindo em maior ou menor grau a relação do locutor/intelocutor com os enunciados dos outros.

\section{Acabamento do Enunciado e os Elementos de Entonação}

Todo enunciado expressa a relação entre os participantes do discurso, assim como é produto desta interação. Para Bakhtin (2003, p. 381) "[...] os sentidos correspondem às respostas as perguntas [...]" e aquilo que não responde a nenhuma pergunta não tem sentido para nós.

O autor do enunciado dá um acabamento de sentido ao todo a partir dos outros enunciados já ditos e não ditos, sobre aquele tema ou objeto, assim como a partir da possível resposta do seu interlocutor.

O enunciado proferido por NAI (16:15:57) explicita a ausência de sentido em relação à pergunta proferida por AVE (16:11:23). Em seguida, o enunciador NAI (16:16:31) percebendo tal situação, solicita que o enunciado seja ignorado. A resposta de AVE (16:19:39), dirigida a TODOS (conectivo) e NAI (vocativo), confirma o pedido. Não apenas NAI (16:16:31) mas TODOS interlocutores devem ignorar tal enunciado, pois ele está incorreto (vazio de sentido).

(16:15:57) NAl fala para TODOS: VOU ME ARRISCAR a falar alguma coisa sobre.... COM BASE no que entendi sobre o que li ...; PARA MI M, o estilo caracteriza o gênero.

(16:16:31) NAI fala para TODOS: VIAJEI.. deletem.

(16:19:39) AVE fala para TODOS: ok, Nai ... deletado

Em uma nova tentativa, NAI (16:21:22) elabora uma outra resposta. A entonação adotada é de caráter declarativo e se manifesta de forma cadenciada.

(16:21:22) NAI fala para TODOS: estilo é criatividade, impressão de marcas individuais; gênero é "modelo"/ concepção/ norma que permite ou não a impressão de um estilo individual.

Temerosa de sua resposta, NAI (16:21:46) recua e solicita uma aprovação. Neste momento, na entonação do enunciado identificamos uma tentativa de negociar a participação dos demais, mesmo que com isto TODOS corram o risco de formular um enunciado parcialmente correto ou mesmo incorreto. Um enunciado tipo delete.

(16:21:46) NAl fala para TODOS: é mais ou menos isso?

Além da orientação dialógica do enunciado expressar algum sentido orientado para o discurso do outro, ele também é orientado socialmente, no sentido de ser conduzido pelo ouvinte/interlocutor enquanto um outro que ocupa determinado lugar social (posição econômica, profissão etc.). A dimensão social está presente em qualquer enunciado, tanto verbal como também gestual e juntamente com a situação social determina a forma discursiva.

As relações de sentido entre diferentes enunciados assumem índole dialógica (ou, em todo caso, matriz dialógica). Os sentidos estão divididos em vozes diferentes [...] (BAKHTIN, 2003, p. 320).

A orientação social no discurso se manifesta tanto na entonação, como na escolha das palavras mais adequadas na correlação existente entre o falante (autor do discurso) e o ouvinte. Destaca-se que a entonação é principalmente a expressão da valoração da situação e do auditório (interlocutores do discurso). Ou seja, os julgamentos de valor, compartilhados por determinado grupo social, aparecem no discurso através da entonação, que está na fronteira do verbal com o nãoverbal, do dito com o não-dito. Ela só pode ser compreendida quando estamos em contato com os julgamentos de valor presumidos por um dado grupo social. 


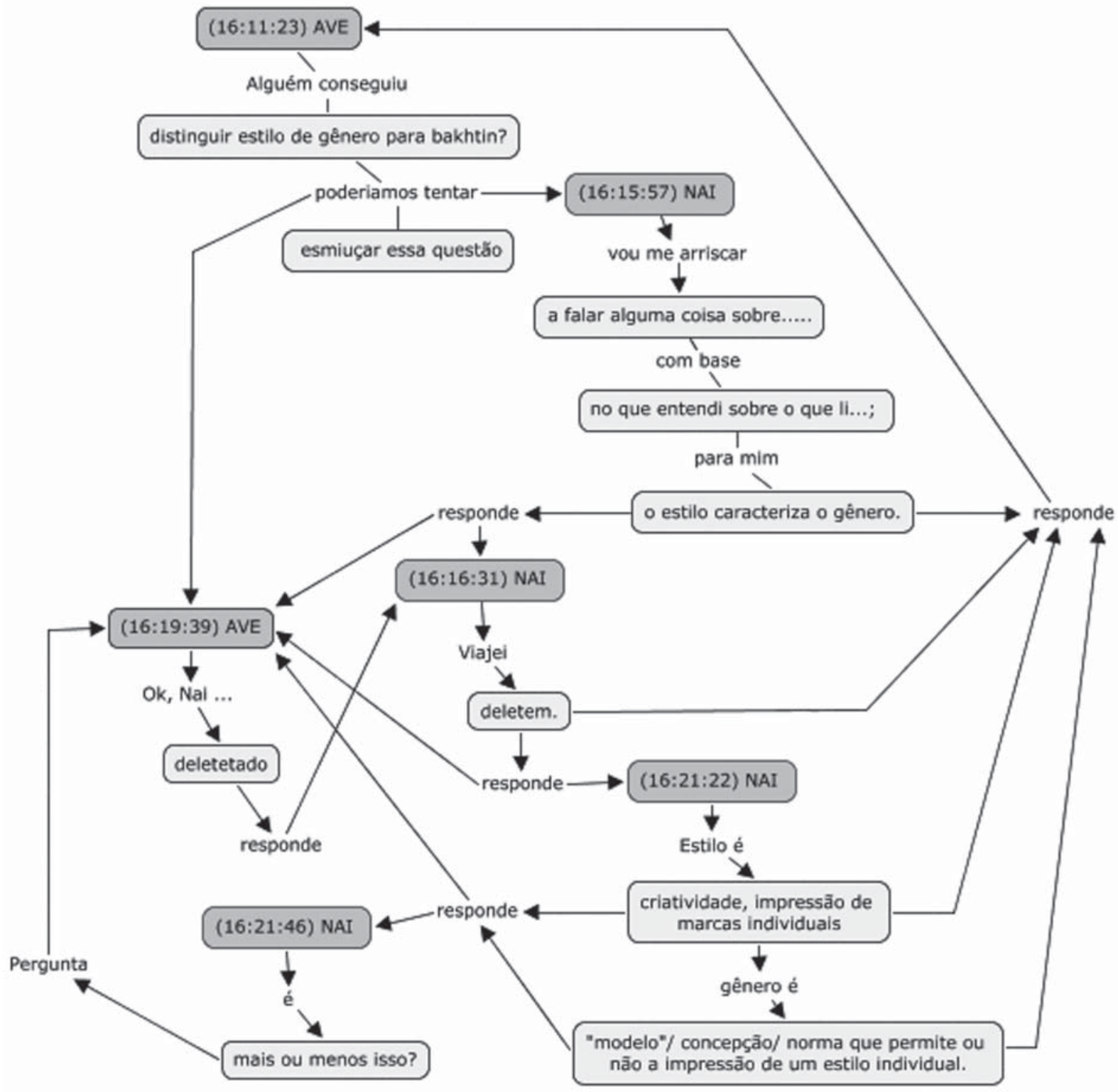

FIGURA 5 - Mapa Conceitual Ilustrando Interações Entre AVE e NAI

De acordo com Bakhtin (2003), a alternância dos sujeitos do discurso é que torna possível identificar os limites de cada enunciado. Quando o falante termina seu enunciado ele passa a palavra ao seu interlocutor possibilitando uma compreensão que é ativamente responsiva.

A alternância dos sujeitos do discurso pode ser identificada através dos elementos de entonação do enunciado. Esses elementos contaminam o enunciado com a expressão do outro, num processo de assimilação da palavra do outro, re-elaborando e re-acentuando os enunciados dos outros.

A entonação que isola o discurso do outro [...] é um fenômeno de tipo especial: é uma espécie de alternância de sujeitos do discurso transferido para o interior do enunciado. (BAKHTIN, 2003, p. 299)

Em resposta ao enunciado provocativo de AVE (16:24:48), em destaque o fragmento "de certa forma, é uma concepção da comunicação verbal que a aproxima da música, concorda Gua?". GUA (16:32:48) realiza um tipo de performance gestual ou vocal verbalizada. Os elementos de entonação identificados explicitam os recursos expressivos adotados por ele. Mediante um discurso irônico, GUA modulariza o seu enunciado. No início ele é formulado com uma tonalidade de surpresa, após de ameaça, em seguida com uma pausa e ao final com um elogio ao lo- 


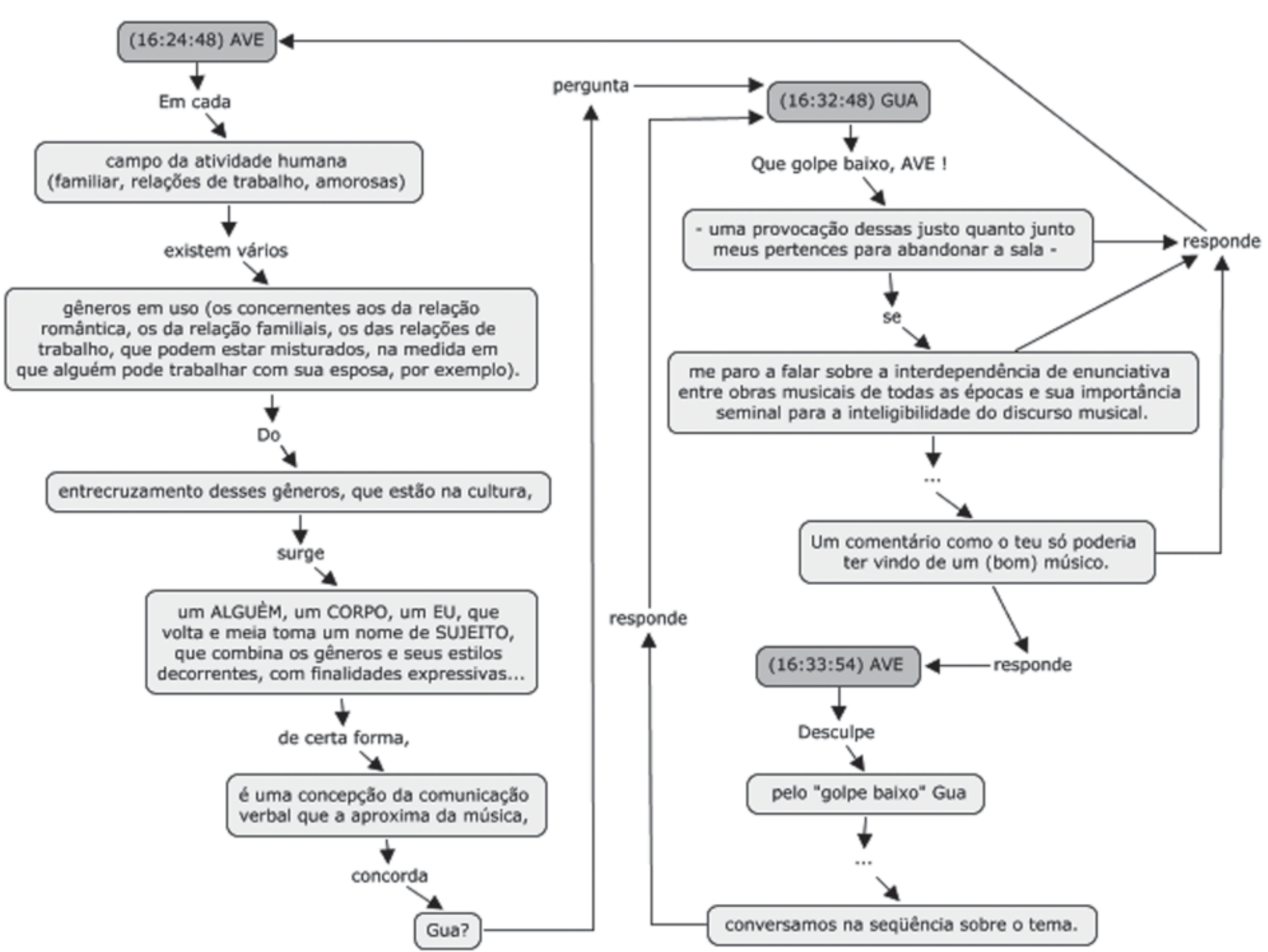

FIGURA 6 - Mapa Conceitual Ilustrando Interações Entre AVE e GUA

cutor. O enunciado passa por transformações de ordem expressiva, demonstra a percepção que GUA teve quanto à situação propícia para sua enunciação e seu zelo em relação ao acabamento.

(16:24:48) AVE fala para TODOS: EM cada campo da atividade humana (familirar, relações de trabalho, amorosas) EXISTEM vários gêneros em uso (os concernentes aos da relação romântica, os da relação familiais, os das relações de trabalho, que podem estar misturados, na medida em que alguém pode trabaIhar com sua esposa, por exemplo). Do entrecruzamento destes gêneros, que estão na cultura, SURGE um ALGUÈM, um CORPO, um EU, que volta e meia toma um nome de SUJEITO, que combina os gêneros e seus estilos decorrentes, com finalidades expressivas... de certa forma, é uma concepção da comunicação verbal que a aproxima da música, CONCORDA GUA?

(16:32:48) GUA fala para AVE: QUE GOLPE BAIXO, AVE ! - uma provocação dessas justo quanto junto meus pertences para abandonar a sala - SE me paro a falar sobre a interdependência de enunciativa entre obras musicais de todas as épocas e sua importância seminal para a inteligibilidade do discurso musical. Um comentário como o teu só poderia ter vindo de um (bom) músico.

Podemos observar que no enunciado GUA (16:32:48), o locutor negocia ao mesmo tempo várias questões: a pergunta efetuada, a impossibilidade de respondê-la, e sua saída do ambiente. Logo em seguida, AVE (16:33:54) responde. Também adotando um discurso irônico, no enunciado de AVE, ecoa um ar de concordância e de postergação.

(16:33:54) AVE fala para TODOS: desculpe pelo "golpe baixo" GUA ... conversamos na seqüência sobre o tema.

\section{Considerações Finais}

Neste artigo buscamos entrelaçar alguns conceitos propostos por Bakhtin a fim de realizarmos uma leitura possível de um Chat que se desenvolveu no contexto de uma disciplina dos cursos de pós-graduação em educação e em informática na educação. A partir do es- 
tudo da interação em Chat em meio a uma disciplina, passamos a nos interrogar sobre a utilização do ambiente para a produção de conhecimento, com base numa interação dialógica, que implica na produção de sentidos. Consideramos o chat propício para discussão conceitual, numa dimensão espaço temporal, permitindo que diferentes participantes pudessem se colocar com suas singularidades expressas nos seus enunciados em forma escrita. A partir da análise dos diferentes enunciados dos participantes no chat foi possível refletirmos sobre a alternância de vozes presentes em uma cadeia dialógica.

Os enunciados escritos nos permitiram elaborar um modelo de análise em forma de gráficos que nos auxiliaram numa ilustração de pragmática comunicacional utilizando conceitos de Bakhtin e os próprios enunciados dos participantes. Os conceitos trabalhados ilustraram a complexa relação entre enunciados, que portam em si relações de sentidos, consolidando relações dialógicas. Trabalhamos com a perspectiva da respondibilidade como estando presente em cada palavra escrita, em cada enunciado proferido no ambiente. Desta forma, consideramos os destinos dos enunciados na relação com o segundo interlocutor e com o terceiro interlocutor. Este último pode mesmo estar fora das interações sincrônicas que se deram no corte temporal de cada encontro sincrônico. Este terceiro nos diz que os destinos de alguns enunciados e palavras proferidas foram acompanhados por nós nos recortes e análise que realizamos, mas também portam em si destinos e desdobramentos de sentido incertos. A análise que aqui elaboramos num outro espaço e tempo, que não dos encontros sincrônicos do chat é uma materialidade dessa abertura que as palavras e os enunciados portam em si para a produção de sentido e conseqüentemente para sua compreendibilidade.

A análise do Chat também nos permitiu compreendê-lo como espaço de polifonia, de entrelaçamento de vozes. Espaço de polifonia, pois as vozes de todos os participantes se encontraram, além de trazerem para o momento de conversa a voz do próprio Bakhtin como participante do diálogo. Nesse espaço de diálogo (ou diálogos, no plural) as vozes de todos os colegas entrelaçaram-se e, através desse encontro, foram produzidos entendimentos possíveis e construção de conhecimento sobre os conceitos de Bakhtin que estavam sendo estudados.

\section{Referências}

BAKHTIN, Mikhail. Marxismo e Filosofia da Linguagem. São Paulo: Hucitec, 1997.

BAKHTIN. Mikhail. Estética da Criação Verbal. São Paulo: Martins Fontes, 2003.

Bernardes, Alexandra Sexto; VIEIRA, Paula Michelle Teixeira. No Discurso Produzido em Salas de Bate-papo da Internet, a Descoberta de um Espaço de Produção de Linguagem. Disponível em: <http://www.anped.org.br/reunioes/24/T1096468548691.doc>. Acesso em: 10 mar. 2008.

BRAIT, Beth. As Vozes Bakhtinianas e o Diálogo Inconcluso. In: BARROS, Diana Luz Pessoa de; FIORIN, José Luiz. Dialogismo, Polifonia, I ntertextualidade. São Paulo: Edusp, 1999. P. 11-28.

BRAIT, Beth. Bakhtin: conceitos-chave. São Paulo: Ed. Contexto, 2005.

BRAIT, Beth. Bakhtin: outros conceitos-chave. São Paulo: Ed. Contexto, 2006.

FIORIN, José Luiz. Introdução ao Pensamento de Bakhtin. São Paulo: Ed. Ática, 2006. 


\section{ANEXO - Extrato do Chat em Análise}

(16:11:23) AVE fala para TODOS: alguém conseguiu distinguir estilo de gênero para Bakhtin? Poderíamos tentar esmiuçar essa questão

(16:13:31) MIS fala para TODOS: diferença entre estilo e gênero... vamos ver...

(16:15:45) GUA fala para AVE: Boa pergunta: desconfio que gênero tem mais a ver com formatos de discurso inerentes a campos comunicacionais, enquanto estilos se referem mais às diferenças individuais no exercício da comunicação discursiva nos diversos gêneros.

(16:15:53) AVE fala para TODOS: sim, é um pouco por aí, GUA, essa é uma noção interessante para Bakhitn... o início do meu discurso, e até mesmo a minha autoria, estão sempre na dependência do outro, mas de um outro que é um pouco mais amplo do que o outro falante, mas engloba a própria cultura. Dessa forma, mesmo a mais simples comunicação interpessoal é um fenômeno, antes de tudo, cultural. Assim como uma obra em vários tomos, como "A comédia humana", de Balzac, é também enunciado, pois também é uma obra posta num circuito de comunicação primordialmente cultural

(16:15:57) NAI fala para TODOS: vou me arriscar a falar alguma coisa sobre..... com base no que entendi sobre o que li...; para mim, o estilo caracteriza o gênero.

(16:16:31) NAI fala para TODOS: viajei.. deletem.

(16:18:50) MIS fala para TODOS: "em cada campo existem e são empregados gêneros que correspondem às condições específicas de dado campo; é a esses gêneros que correspondem determinados estilos" (p. 266). Agora traduzam hehe

(16:19:39) AVE fala para TODOS: ok, Nai... deletado

(16:21:22) NAI fala para TODOS: estilo é criatividade, impressão de marcas individuais; gênero é "modelo"। concepção/ norma que permite ou não a impressão de um estilo individual.

(16:21:46) NAI fala para TODOS: é mais ou menos isso?

(16:24:48) AVE fala para TODOS: em cada campo da atividade humana (familirar, relações de trabalho, amorosas) existem vários gêneros em uso (os concernentes aos da relação romântica, os da relação familiais, os das relações de trabalho, que podem estar misturados, na medida em que alguém pode trabalhar com sua esposa, por exemplo). Do entrecruzamento destes gêneros, que estão na cultura, surge um ALGUÈM, um CORPO, um EU, que volta e meia toma um nome de SUJEITO, que combina os gêneros e seus estilos decorrentes, com finalidades expressivas... de certa forma, é uma concepção da comunicação verbal que a aproxima da música, concorda Gua?

(16:32:48) GUA fala para AVE: Que golpe baixo, AVE ! - uma provocação dessas justo quanto junto meus pertences para abandonar a sala - se me paro a falar sobre a interdependência de enunciativa entre obras musicais de todas as épocas e sua importância seminal para a inteligibilidade do discurso musical. Um comentário como o teu só poderia ter vindo de um (bom) músico.

(16:33:54) AVE fala para TODOS: desculpe pelo "golpe baixo" GUA... conversamos na seqüência sobre o tema.

\section{André Luis Marques da Silveira}

Professor adjunto do Centro Universitário Ritter dos Reis (UNIRITTER) e da Escola Superior de Propaganda e Marketing (ESPM) andre@um.pro.br

\section{Magale Machado}

Psicóloga, mestre em Educação, doutoranda do Programa de Pós-Graduação em Educação pela Universidade Federal do Rio Grande do Sul (PPGEdu/UFRGS)

magalemachado@gmail.com

Simone Bicca Charczuk

Psicóloga, doutoranda do Programa de Pós-Graduação em Educação da Universidade Federal do Rio Grande do Sul (PPGEdu/ UFRGS)

sibicca@gmail.com 